\title{
The impact of mobile information services on the quality of life of Internet users in Japan
}

\author{
Fumiyo N. Kondo *, Qazi Mahdia Ghyas `
}

\begin{abstract}
This paper aims to identify and examine the relationships between individual life domains of mobile information services (MIS) and the overall domain, and their impact on the quality of life (QoL) of Japanese Internet users. Questionnaires were distributed online to Japanese Internet users aged 15 to 69, sampled from Japan's Internet population. We obtained 2,997 effective responses, or $72.1 \%$ of the entire sample. Comprehensive analyses of the relationships between constructs were conducted using PLS-SEM as this analytical method is appropriate for a model with a reflective construct and formative constructs. The results based on the bottom-up spillover theory clearly indicated that the relationship between individual and overall contribution in the specified model is valid and reliable for analysis. The contribution of the health life domain has the highest influence on the overall contribution to the QoL for Japanese Internet users as demonstrated by this study for the first time. Further, positive significant individual domains were noted in a descending order, as follows: cultural life domain, trustworthy life domain, leisure life domain, consumer life domain, and safety life domain.
\end{abstract}

Keywords: bottom-up spillover theory; health service; mobile information services; PLS-SEM; quality of life; Internet sample

\footnotetext{
* University of Tsukuba, Division of Policy and Planning Sciences, Faculty of Engineering, Information and Systems, Ibaraki, Japan, kondo@sk.tsukuba.ac.jp

† International University of Scholars, Dhaka, Bangladesh, ghyas.mahdia.ma@alumni.tsukuba.ac.jp
} 


\section{Introduction}

The value of information depends on users and contexts, as information has dynamic attributes. Five key characteristics of information have been summarized [1] as follows: value, multiplicative quality, dynamics, life cycle, and individuality as the nature of intangibility. Apart from the five attributes, the following can also be added as attributes: the alleviation of uncertainty [2], interdependency [3], and context dependency, cultural dependency [4], medium dependency, and conversion dependency. The value of information can differ depending on individual situations. Information has also been characterized as a dynamic force, "constantly altering and extending a store of knowledge" [5]. Therefore, it is important to continuously address the impact of mobile information services (MIS) on the overall quality of life (QoL) as a social outcome with respect to the changing situations of consumers.

Reference [6] mentions that service evaluation might have a strong influence on both social (e.g., QoL) and traditional economic outcomes (e.g., profitability, loyalty, or service continuance). Some studies have addressed the impact of mobile computing on the overall QoL as a social outcome, rather than as economic outcomes as an instrument of satisfaction [7] or for the intention to use it [8]. According to the insights obtained from this study, a company will be able to provide consumers with valuable MIS, whose purchase, usage, and experience make them happy in those life domains and benefit them. In turn, the company will benefit from the value that the consumers have paid for.

Eleven relationships have been proposed [9] between the individual and overall contribution of QoL in Korea and Japan, some of which have been found to have a stronger influence on the overall contribution. Reference [10] and [11] measured the relationship between MIS and QoL of Japanese students, and tested a hypothesis regarding each variable's positive coefficient. Moreover, these studies examined the contribution of life domains to the QoL using MIS based on the bottom-up spillover theory. The two research methods have indicated the model's applicability on young Japanese students and reveals the expanding needs of MIS. This study aims is similar to these two research studies, and it uses Japan's Internet user population. Studies of young students were useful in grasping emerging MIS trends as early warning indicators, but the results do not represent the entire Internet population of different age ranges. We attempt to bridge the gap between studies on students' need of MIS and studies of the entire Internet population. The purpose of this paper is to identify and examine the relationships between individual life domains of mobile information services (MIS) and the overall domain, and their impact on the quality of life (QoL) of Japanese Internet users by using PLS-SEM method. The originality of this study is to provide results based on Japan's Internet user population, in which accuracy for capturing emerging needs of mobile information services is assured and limitation or bias that might have been existed in prior studies can be prevented by representative samples on Japan's Internet user population.

The remainder of the article is organized $\mathrm{n}$ as follows: The next section describes the theoretical background, including the overall QoL, the individual life domains, the bottom-up spillover theory, and the contribution to the QoL. The third section analyzes the data and presents the methodology and results. The final sections summarize the discussion, conclusions, implications, and directions for future research. 


\section{Theoretical Background}

\subsection{Quality of Life (QoL)}

Various scholars have defined the term "QoL" in different ways; for example, [12] defines QoL as the "necessary conditions for happiness," while [13] defines it as subjective well-being. Further, many terms are used to represent well-being, such as "standard of living," "human well-being," and "welfare." QoL is a measure of how happy or fulfilled people are in terms of their various wants and needs.

Diverse areas have studied QoL, such as marketing [14], health [15, 16], and education [17]. However, to our knowledge, no study has been conducted on an Internet population in the area of telecommunication services. Thus, we attempt to empirically measure the contributions of MIS. We also strive to establish a theoretical model that explicitly determines the relationship between MIS and the QoL of Japan's Internet population based on a representative sample.

\subsection{Individual Life Domains}

Researchers studying QoL have identified many distinct life domains, which encompass the various places, things, activities, roles, and relationships in which a person is typically involved [18]. These studies posit that people actually experience and store their various life events in distinct domains that are associated with leisure, family, friend, cultural, work, community, consumer, finance, health, safety, and self-life. These eleven life domains have been examined for mobile data services concerning Japan and Korea [9]. Four other life domains include education [18, 19], home-healthcare [20], trustworthy [20] and informational life domain [21].

As mobile phone usage has blurred the boundaries between home and work [22], MIS can be used across space and time [23]. Therefore, MIS has the potential to affect many life domains depending on timing and context. Moreover, we want to clarify the MIS domains that are most relevant to the overall QoL.

\subsection{Bottom-up spillover theory}

The bottom-up spillover theory [18] describes the relationship between individual life domains and the overall QoL domain. The theory indicates that the QoL in individual domains has spillover effects on the overall QoL. In other words, happiness in subordinate individual life domains can spill over to produce superordinate overall happiness [18]. The bottom-up spillover theory has been incorporated into the satisfaction hierarchy model, which states that overall life satisfaction is functionally related to the satisfaction in each of the individual life domain. This can be measured by the satisfaction from specific events in each life domain [14]. 


\subsection{Contribution to QoL}

The basic premise of the bottom-up spillover theory is that satisfaction levels within individual life domains affect the overall level of life satisfaction [14]. When the bottom-up spillover theory was applied to MIS, satisfaction was replaced with improvement in aspects of the QoL. Figure 1 illustrates the relationship between the individual and overall contribution of our research model. The model's bottom layer represents the contribution of the MIS to the QoL in the corresponding domains (hereafter, individual contributions). The contribution of MIS to the quality of individual life domains can be measured by the perceived contribution of MIS to specific use-experiences in the respective life domain. Let X1-X3 in Figure 1 be the formative measurements (or indicators) for the underlined latent variable (or construct) of Life Domain 1 or community life. Similarly, the other measurements X4-X45 involve the other fourteen life domain constructs. Our model's top layer represents the specific contribution of MIS to the overall QoL (hereafter, overall contribution). As regards the individual contributions, the overall contribution is conceptualized as the perceived contribution of MIS to the overall QoL. OVR 1-OVR 4, depicted in Figure 1, are the reflective measurements of life in terms of ideality, improvements, satisfaction, and achievements for the overall life construct.

Past studies suggest that IT does influence users' QoL. For example, a study on the adoption behavior for hedonic systems [24] indicates that IT may affect leisure or cultural life. Reference [25] explains users' continuance behavior in online banking systems to demonstrate that such systems affect the QoL in the financial life domain. Reference [9] measured a mobile data service technology's contribution to users' QoL. They also examined eleven individual life domains for Korean and Japanese respondents. By including four additional domains, [10] examined the following 15 life domains for young Japanese respondents: community, consumer, cultural, education, family, financial, friend, health, home healthcare, informational, leisure, safety, and self-life, trustworthy, and work life domains. We examine the same 15 life domains, then utilize a representative sample of the entire Internet population. Our measures concern the spillover of contributions to the QoL by using MIS. Therefore, the contributions of MIS to QoL within individual life domains are specified to express their influence on the contribution of MIS to overall QoL in a model. We used two control variables, age and gender, to adjust for differences in the values of the two variables. Figure 1 displays our research model, and we hypothesize that improving QoL in each life domain by using MIS positively influences the overall QoL of the Japanese Internet population. 


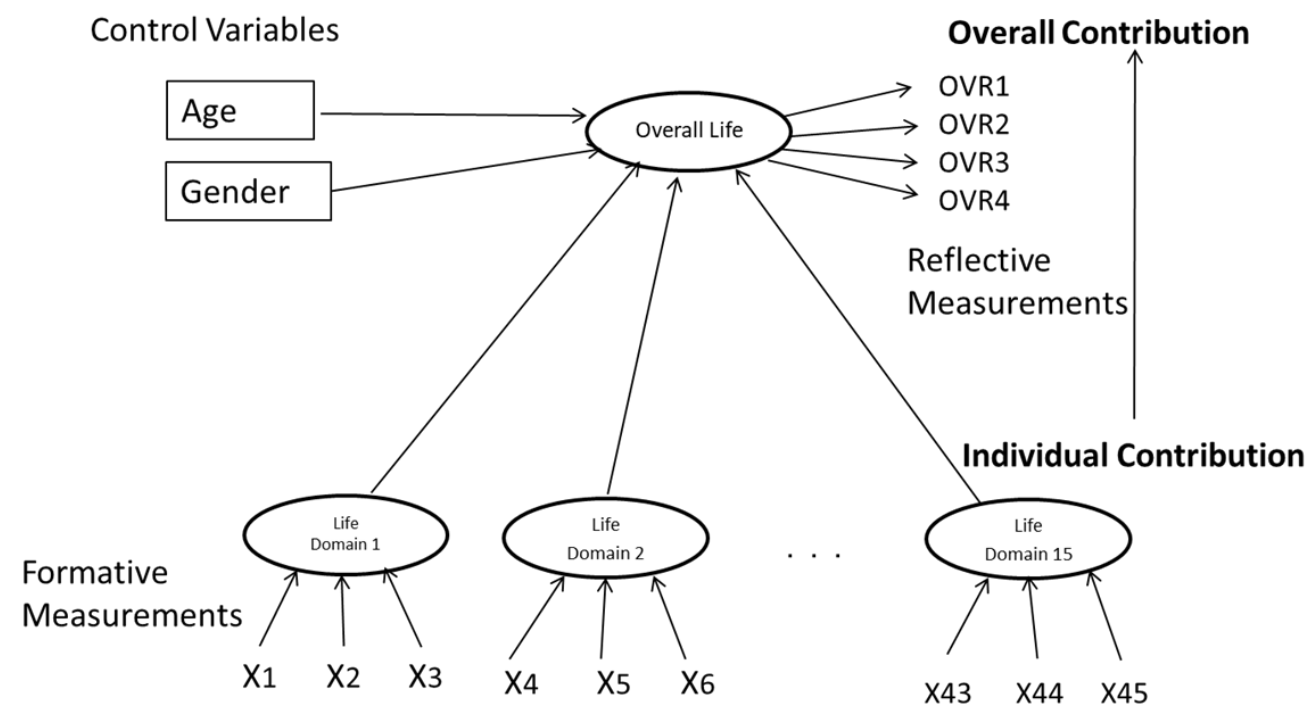

Figure 1: Relationship between individual contributions and overall contribution

\section{Analytical Method}

\subsection{Data}

An online questionnaire was distributed by a professional research firm to 4,157 Japanese Internet users aged 15-69, during the period February 2-7, 2017. The research company sent an e-mail to each panel member to notify them of the survey and provide them with the URL for the questionnaire to let them start the survey. The Internet user population covers $82 \%$ of the Japanese population [26]; in other words, only $18 \%$ of the Japanese population is not covered, so the respondents' IT literacy would be slightly higher than the average of the entire population in this age range. This affects the results, but not severely. We obtained 2,997 effective responses, or $72.1 \%$ of the entire sample. This data set is a quota sample of panel monitors of the Japanese Internet population with gender, age, and area to match the ratio. 
We chose to use the formative indicators elicited to reflect concrete use experiences with MIS, as the bottom-up spillover theory, our theoretical foundation, required highly specific events and experiences at the bottom of the improvement hierarchy model. Table 1 presents the effective participants' demographic information. Our online survey was conducted using an Internet population aged 15-69 at the beginning of February 2017. The survey in [10] involved 105 students at a university in 2015. The data were biased in age and gender, 49\% were 18-19 year olds and $51 \%$ were in their 20 's, and $76 \%$ were male and $24 \%$ were female. The survey in [9] included 1038 consumers from all ranges of ages, however, the age distribution was limited to $1 \%$ of teens and one collapsed cell of 40 or older in the period 2005-2006. Compared with the sample from [9] for the period 2005-2006, our sample for 2017 properly accounts for the Internet population, with a smaller ratio of only $8 \%$ of the individuals in their $60 \mathrm{~s}$, the oldest age range.

Table 1: Demographics of Respondents by Year

\begin{tabular}{|l|l|r|r|}
\hline \multicolumn{2}{|c|}{ Category } & \multicolumn{2}{c|}{2017} \\
\hline \multirow{3}{*}{ Gender } & Male & 1443 & $48 \%$ \\
\cline { 2 - 4 } & Female & 1554 & $52 \%$ \\
\hline \multirow{5}{*}{ Age } & 19 years or younger & 96 & $3 \%$ \\
\cline { 2 - 4 } & $20-29$ years & 617 & $21 \%$ \\
\cline { 2 - 4 } & $30-39$ years & 710 & $24 \%$ \\
\cline { 2 - 4 } & $40-49$ years & 816 & $27 \%$ \\
\cline { 2 - 4 } & $50-59$ years & 522 & $17 \%$ \\
\cline { 2 - 4 } & 60 years or older & 236 & $8 \%$ \\
\hline
\end{tabular}

Subjects were asked to rate the extent to which they agree that each specific MIS use experience contributes to their QoL through the corresponding individual life domains. We partially utilized the measurements in [9] with the following changes. As the phrase "downloading the latest ringtones and logos" in the measurements for leisure, family, and self-life used by [9] is out of date, we changed it to "using SNS, such as Facebook or Twitter." This change may prevent the negative reverse weights that occur due to high collinearity among the measurements reported in [11]. We constructed questions measuring the overall contribution of MIS to QoL as reflective indicators based on a modified satisfaction-with-life scale (SWLS) or as we call it an improvement-with-life-scale (IWLS). We used sets of 7-point Likert scales, ranging from strongly disagree to strongly agree to measure both the individual and overall contributions. 


\subsection{Analytical Method}

We used a component-based structural analysis technique, which included partial least squares structure equation modeling (PLS-SEM) instead of a conventional approach with covariance-based structural equation modeling (CB-SEM). The PLS analysis is particularly suited to cases in which CB-SEM reaches its limits. Further, the PLS method is well-suited to handle both formative indicators (for individual contributions) and reflective indicators (for overall contribution) in one model [27]. The PLS has been successfully applied to construct a theory of mobile data service contribution to the QoL of young Japanese mobile users [10, 11]. The validity and reliability of the measures were tested using PLS-SEM. Then, the research models were analyzed with the data of Japan from 2017 via PLS by using the Smart-PLS statistical software, version $2.0 \mathrm{M} 3$.

\subsection{Validity and Reliability of the Measures}

There are two types of measurement scales in structural equation modeling: formative and reflective. Both these measurement scales were present in the research model in [9]. While PLS is appropriate for handling both formative and reflective indicators [27], we separately assess the two constructs because the criteria for assessing them are different. The loadings in PLS represent the influence of individual-scale items on reflective constructs [28].

The reflective measurement scale's indicator reliability, internal consistency reliability, or discriminant validity should be fully examined [29]. Therefore, we assess the reflective constructs' reliability and validity by checking the factor loadings as the confirmatory factor analysis, composite reliability (CR), and average variance extracted (AVE) for overall contribution, as noted in Table 2. The measurements in this table, or OVR 1-OVR 4 in Figure 1, represent the measurements of the overall life domains. The results indicate that all measured items have convergent validity at the indicator and construct levels, which also reveals the indicators' internal consistency. The weights in PLS represent the comparable influence on formative constructs [28]. Thus, we examine the weights of the formative constructs, multicollinearity, and discriminant validity. The multicollinearity problem of the indicators may occur in a formative measurement model if the indicators are highly correlated with each other. We generated variance inflation factor (VIF) and tolerance values to check for multicollinearity. All collinearity statistics or the VIF values for the formative constructs of individual life domains in Japan for 2017 were less than 5, which indicates that the multicollinearity problem is not severe [29]. 
Table 2: Reliability and Validity of Overall Contribution in Japan for 2017

\begin{tabular}{|l|r|r|r|r|}
\hline \multirow{2}{*}{ Evaluation Criteria } & \multicolumn{4}{|c|}{ Reflective Indicator (Overall Contribution) } \\
\cline { 2 - 5 } & OVR 1 & OVR 2 & \multicolumn{1}{|c|}{ OVR 3 } & \multicolumn{1}{|c|}{ OVR 4 } \\
\hline $\mathrm{CR} \geq 0.70$ & 0.95 \\
\hline $\mathrm{AVE} \geq 0.50$ & 0.89 & 0.93 & 0.93 & 0.86 \\
\hline Loading $\geq 0.50$ & 132.86 & 234.91 & 245.44 & 130.34 \\
\hline t-value at $\mathbf{p}<\mathbf{0 . 0 0 1}$ & \multicolumn{4}{|c}{} \\
\hline
\end{tabular}

As recommended by [29], we used a standard bootstrapping procedure with 5,000 samples to test for convergent validity. The weights and $t$-statistics of all formative indicators were found to bear significant relationships at the $1 \%$ significance level within the corresponding life domains. Moreover, each question item was weighted as positive, resulting in the securing of an appropriate level of convergent validity to measure individual contributions.

\section{Results}

We tested the model's nomological validity with 15 life domains to determine whether the domain-specific contributions of MIS to QoL exhibits a significant relationship with the overall contribution of MIS to QoL. Table 3 indicates that the R-squared coefficient of determination for 2017 was 0.52 , or approximately the same as the 0.51 value for Japan's 2007 data on overall population. This indicates an acceptable fit; hence, the 15 individual life domains moderately explain $52 \%$ of the variance in overall contribution based on the representative Internet sample. Therefore, our model's 15 life domains are useful for forecasting the overall QoL. The overall and individual contributions were found to have appropriate levels of reliability and validity for the Japanese Internet sample.

According to the theoretical model in [9], the individual contributions of MIS influence its overall contribution. That is, we discovered that the feeling of improvement in individual domains of QoL by using MIS will lead to the belief in the improvement of the overall QoL by using MIS (close to ideal life, improvements in life, satisfaction in life, achievements in life). We identified 15 life domains that are closely related to overall QoL by conducting a PLS analysis using a bootstrap method with 5,000 samples, as recommended by [29]. We estimated the path coefficients between individual and overall contributions, as presented Table 3 . 
In the measurements for leisure, family, and self-life, a question was changed to exclude the phrase "downloading the latest ringtones and logos" and include "using SNS, such as Facebook or Twitter." This generated weights that are all positive except in the self-life life domain, which is insignificant and negative, but close to zero. As the negative was an exception and was not significant, the change generated appropriate results.

The results from the 2017 Internet population's representative sample indicate that at the $1 \%$ level, the contributions to six individual life domains had a positive and significant impact on the overall contribution of MIS. There were 12 significant coefficients in the 2015 student data, but with contradictory negative coefficients on the paths from individual life domains to the overall life domain. The results in the 2017 representative Internet population sample have no contradictory negative coefficients and generated reasonable and stable results. The coefficients of the two control variables, age and gender, are not significant, indicating that the influence by the parameters on the main independent variable is very small. The results indicate that the contribution to the health life domain has the largest influence on the overall contribution, with $\beta$ $=0.33$ initially. This was followed by the cultural $(\beta=0.18)$, leisure $(\beta=0.14)$, trustworthy $(\beta=$ $0.15)$, consumer $(\beta=0.08)$, and safety $\beta=0.07)$ life domains. The last two were marginally significant. All of the five variables except for consumer life domain are statistically significant for the 2015 student data, and the variables were found to be both important and stable.

Table 3: Path coefficients between individual contributions and overall contribution

\begin{tabular}{|l|cr|}
\hline Hypotheses & $\begin{array}{l}\text { Path } \\
\text { coefficients }\end{array}$ \\
\hline Health Life --> Overall Life & $\mathbf{0 . 3 3} \quad * * *$ \\
\hline Cultural Life --> Overall Life & $\mathbf{0 . 1 8} \quad * * *$ \\
\hline Trustworthy Life --> Overall Life & $\mathbf{0 . 1 5} \quad * * *$ \\
\hline Leisure Life--> Overall Life & $\mathbf{0 . 1 4} \quad * * *$ \\
\hline Consumer Life --> Overall Life & $\mathbf{0 . 0 8}$ & $*$ \\
\hline Safety Life --> Overall Life & $\mathbf{0 . 0 7}$ & $*$ \\
\hline Community Life --> Overall Life & -0.04 & \\
\hline Informational Life --> Overall Life & 0.04 & \\
\hline $\begin{array}{l}\text { Home-healthcare Life --> Overall } \\
\text { Life }\end{array}$ & -0.04 & \\
\hline Financial Life --> Overall Life & -0.00 \\
\hline Family Life --> Overall Life & -0.03 \\
\hline Work Life --> Overall Life & -0.01 \\
\hline Friend Life --> Overall Life & 0.02 \\
\hline Self-life --> Overall Life & -0.02 \\
\hline Educational Life --> Overall Life & -0.02 \\
\hline Age & 0.02 \\
\hline Gender & 0.00 \\
\hline R value & 0.52 \\
\hline
\end{tabular}

(Note: N/A represents "Not Applicable"; ***p $<0.001 ; * * p<0.05 ; * p<0.1$.) 
The coefficient for consumer life was positive for the 2017 Internet data, which can be considered as reasonable. Consumer life for 2017 had a positive and significant effect on the overall QoL. The variables that were positively significant for individual life domains in the 2015 student data were home- healthcare, financial, informational, and community life domains. These became insignificant for the 2017 nationwide representative data, which could indicate reasonable results.

The respondents were asked an additional question regarding their health status, as presented in Table 4. Out of the entire 2017 Internet sample, 30.9\% responded with "there is something wrong with my health," whereas the figure is $22.1 \%$ for the 2015 student sample. This may be why the path from health to overall life was the largest in 2017.

Moreover, the questionnaire also inquired about health control needs, with multiple answers, which are presented in Table V. The strongest need was "[p]reparation of healthy meals and nutrition control," followed by a "[1] ack of exercise and no idea how to exercise," and "[c]oping with various body conditions." It is noteworthy that health control needs are strong. Further, slightly less than $95 \%$ of the Internet users pay less than 3,000 yen per month for all MIS (Table 4). Therefore, there are opportunities of providing such MIS at inexpensive prices.

Table 4: Health status

\begin{tabular}{|c|c|c|}
\hline Health Status & Frequency & $(\%)$ \\
\hline $\begin{array}{l}\text { Feel good and have no problems performing } \\
\text { daily activities }\end{array}$ & 1806 & 60.3 \\
\hline $\begin{array}{l}\text { There is something wrong with my health, but I } \\
\text { have no problem in performing daily activities }\end{array}$ & 689 & 23.0 \\
\hline $\begin{array}{l}\text { There is something wrong with my health and I } \\
\text { have some problem in performing daily } \\
\text { activities }\end{array}$ & 197 & 6.6 \\
\hline $\begin{array}{l}\text { There is something wrong with my health, and I } \\
\text { need help from others to perform daily activities }\end{array}$ & 35 & 1.2 \\
\hline Able to carry out daily activities unassisted & 270 & 9.0 \\
\hline Total & 2997 & 100.0 \\
\hline
\end{tabular}


Table 5: Health control Needs

\begin{tabular}{|l|r|r|}
\hline \multicolumn{1}{|c|}{ Health Control Needs } & Frequency & (\%) \\
\hline $\begin{array}{l}\text { Preparation of healthy meals } \\
\text { and nutrition control }\end{array}$ & 1954 & 65.2 \\
\hline $\begin{array}{l}\text { Lack of exercise and ideas on } \\
\text { how to exercise }\end{array}$ & 1310 & 43.7 \\
\hline $\begin{array}{l}\text { Difficulty taking daily } \\
\text { medication and adjusting their } \\
\text { doses }\end{array}$ & 285 & 9.5 \\
\hline $\begin{array}{l}\text { Coping with varying body } \\
\text { conditions }\end{array}$ & 721 & 24.1 \\
\hline \multicolumn{1}{|c|}{ Total } & 2997 & 100.0 \\
\hline
\end{tabular}

Table 6: Payment per month for service or application in 2017

\begin{tabular}{|l|r|r|}
\hline Payment per Month & Frequency & \multicolumn{1}{l|}{$\%$} \\
\hline Less than 3000 yen & 2819 & 94.1 \\
\hline $\begin{array}{l}3000 \text { yen or more } ~ \\
5000 \text { yen }\end{array}$ & 115 & 3.8 \\
\hline $\begin{array}{l}53000 \text { yen or more } \sim \\
8000 \text { yen }\end{array}$ & 37 & 1.2 \\
\hline $\begin{array}{l}8000 \text { yen or more } \sim \\
10000 \text { yen }\end{array}$ & 17 & 0.6 \\
\hline 10000 yen or more & 9 & 0.3 \\
\hline \multicolumn{1}{|c|}{ Total } & 2997 & 100.0 \\
\hline
\end{tabular}

Then, the relationship between the construct health life and health control needs and indictor variables gender and age range were examined using a regression analysis. We calculated the expected variable of latent health life domain (hereafter, Health Life score), by multiplying each weight by the measurements and adding them up as a dependent variable. Then, the Health Life score was regressed on the explanatory variables to determine the factors that influence it. 
We found that except the indicators of age range, that other explanatory variables were positively significant. Further, exercise needs have the largest influence on the Health Life score, followed by healthy meal preparation, coping with varying body condition, daily medication, and gender. The indicator value was specified to take a value of one for male. Its negative coefficient indicates that females are more concerned about the health life domain than males, which is an expected result. The determinant variable, R-squared, was only 0.032 , explaining only $3.2 \%$ of the variation in the Health Life score.

Table 7: Coefficient of health control needs

\begin{tabular}{|l|r|rr|}
\hline & Coefficient & t-value & \\
\hline Constant & 4.239 & 75.020 & $* * *$ \\
\hline Healthy meals & 0.330 & 6.958 & $* * *$ \\
\hline Exercise & 0.339 & 7.499 & $* * *$ \\
\hline $\begin{array}{l}\text { Daily medica- } \\
\text { tion }\end{array}$ & 0.238 & 4.793 & $* * *$ \\
\hline Body conditions & 0.237 & 3.326 & $* * *$ \\
\hline Gender & -0.086 & -2.061 & $* *$ \\
\hline
\end{tabular}

(note: $* * * \mathrm{p}<0.001 ; * * \mathrm{p}<0.05$.)

Figure 2 shows a summary of results that improving QoL in six life domains by using MIS positively influences the overall QoL of the Japanese Internet population in terms of ideality, improvements, satisfaction, and achievements in life. The largest contribution was from Health Life domain.

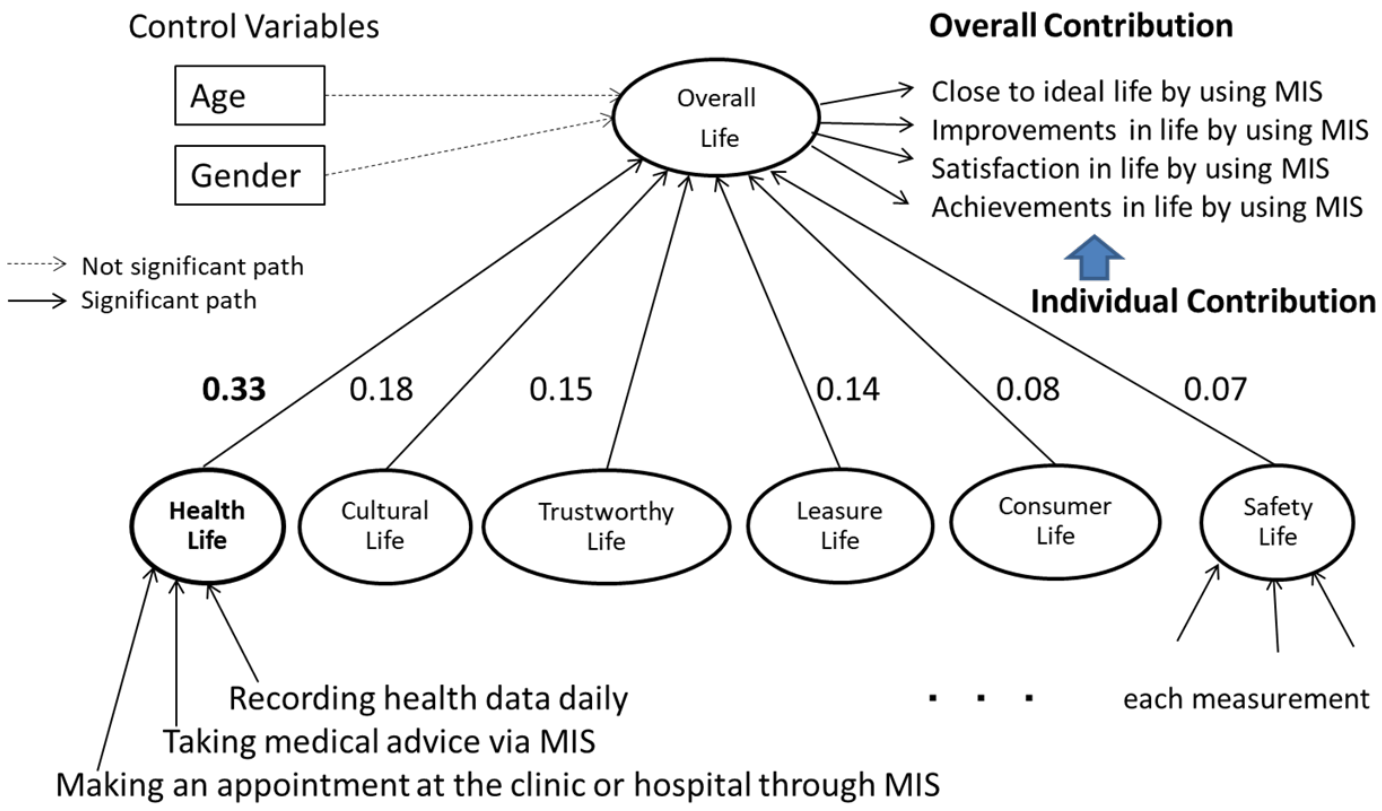

Figure 2: Relationship between Overall and Individual Life Domains with Positive Effects 


\section{Findings and Future Research}

We successfully applied the bottom-up spillover theory to the use of MIS by Japanese Internet users by utilizing 15 life domains to measure the contribution to QoL. This study revealed that the following six life domains have positive and significant effects on the overall contribution: health, cultural, leisure, trustworthy, safety, and consumer life domains. The first five life domains are significant, indicating stable results that are similar to those for the data on young Japanese users of 2015 [11]. Some changes to more positive significant individual domains occurred between 2005-2006 and 2017. Further, the health life domain had the largest effect on the overall contribution for the Japanese Internet users of 2017. The results revealed that there are potential needs for MIS markets in the six life domains. Further, the health life domain has the greatest impact on the overall quality of life. The results of the additional regression analysis indicated that the variables of gender and health control needs have a positive relationship with the estimated Health Life score. The value of R-squared for the regression analysis is very low, future research need to find out other independent variables to explain the dependent variable. Additional questions on specific needs for each domain and the subsequent analyses will provide some hints to the future development of MIS. Future research could identify potential markets by determining how Internet users actually search for related information services in the life domains.

\section{Conclusion}

This study primarily aimed to examine MIS needs for improving the quality of life of the Japanese Internet population. The study assessed the relationships among the model's constructs by applying the bottom-up spillover theory and using 15 life domains to measure their contributions to QoL. The results from this study clearly indicated that the relationship between the model's individual and overall contributions are valid and reliable for measuring the contributions of MIS to the QoL of users based on the bottom-up spillover theory.

\section{Acknowledgement}

This work was supported by Grants-in-Aid for Scientific Research No. 17K03989, from the Ministry of Education of the Government of Japan. 


\section{References}

[1] J.J. Eaton and D. Bawden, "What kind of resource is information?" International Journal of Information Management, 11(2), 1991, 156-165.

[2] A. Mark and L. Pierce The social nature of information. Library Trends , 49(3), 2001, $472-485$.

[3] N. Röling, The agricultural research-technology transfer interface: a knowledge systems perspective. In D. Kaimowitz (Ed.), Making the link: agricultural research and technology transfer in developing countries , (pp. 1-42). Boulder, CO: Westview Press, 1990.

[4] W.R. Pickering, "Principia informatica: Conversations with R.T. Bottle." Journal of Information Science, 22(6), 1996, 447-456.

[5] A. Rogers, Adults learning for development. London: Cassell, 1992.

[6] T.S. Dagger and C.J. Sweeney "The effect of service evaluations on behavioral intentions and quality of life.” Journal of Service Research, 9(1), 2006, 3-18.

[7] M.S. Choi, H. Choi, Y.C. Kim, and J. Kim, "An empirical study on post-adoption behavior of mobile data service with a focus on comparison between services." Korean Marketing Review, (20) 1, 2005, 1-27.

[8] K.C.C. Yang, "Exploring factors affecting the adoption of mobile commerce in Singapore." Telematics and Informatics, (22) 3, 2005, 257-277.

[9] H. Choi, J. Kim, M. Lee, G. Gaglis, K. Naruse, I. Constantious, E. Fife, and E.G Mayhew, "Contribution to quality of life: Cross-national validation of new metrics for mobile data service technology in Korea and Japan." International Journal of Innovation and Technology Management, 4(2), 2007, 1-208.

[10] Q.M. Ghyas, and F.N Kondo, "How Do Mobile Information Services Improve Quality of Life? The Case of Japanese Students." International Journal of Innovation and Technology Management, (13) 6, 2016.

[11] F.N. Kondo, and Q.M. Ghyas, "Expansion of mobile information service needs toward improving quality of life in Japan. Proceedings of the 5th IIAI International Congress on Advanced Applied Informatics" 2016, pp. 1120-1125.

[12] S. McCall, "Quality of Life.” Social Indicators Research, 16, 1975, 299-349.

[13] K.W. Terhune, Probing Policy Relevant Questions on the Quality of Life. In The Quality of Life Concept. Washington, DC: Environmental Protection Agency, 1973.

[14] M.J. Sirgy, The Psychology of Quality of Life. Dordrecht: Kluwer Academic Publishers, 2002. 
[15] K.L. Leung, S.P. Kwok, S.C. Lam, J.F. Lee, R.Y. Yiu, S.S. Ng, P.B. Lai, and W.Y. Lau, "Laparoscopic resection of rectosigmoid carcinoma: Prospective randomized trial." Lancet, 363, 2004, 2224-2229.

[16] G. Takahashi, Y. Otori, M. Urashima, Y. Kuwayama, Q Committee "Evaluation of quality of life in Japanese glaucoma patients and its relationship with visual function." Journal of Glaucoma, 25( 3), 2016, 150-6

[17] E.S. Huebner, and R. Gilman, "An introduction to the multidimensional students' life satisfaction scale." Social Indicators Research, 60, 2002, 115-122.

[18] F.M. Andrews, and S.B. Withey, Social indicators of well-being: America's perception of life. New York: Plenum Press, 1976.

[19] H. Choi S.K. Im, M. Lee, and J. Kim, . Contribution to quality of life: A new outcome variable for mobile data service. Journal of the Association of Information System, 8(12), Article 1, 2007b, 598-618.

[20] G. Jing, and K. Andy, Mobile application development for senior citizens.PACIS 2010 Proceedings, Paper 214-223.

[21] L. Nguyen, S. Evans, W.D. Wilde, and G. Shanks, Supporting information needs of senior citizens in community aged care. ACIS 2010 Proceedings, Paper 7.

[22] L. Haddon, Il controllo della comunicazione. Imposizione di limiti all'uso del telefono. In L. Fortunati (Ed.), Telecomunicando in Europa. Milano: Franco Angeli, 1998,.

[23] L. Palen, Mobile telephony in a connected life. Communications of the ACM, 45(3), 2002, 78-82.

[24] V.D. Heijden, User acceptance of hedonic information systems. MIS Quarterly (28: 4) 2004.

[25] A. Bhattacherjee, "Understanding information Systems Continuance: An Expectation-Confirmation Model," MIS Quarterly (25) 3, 2001, pp. 351-370.

[26] Trends of Device Usage in Multi-device Usage Research (in Japanese), accessed as of March 10, 2017, http://www.intage.co.jp/library/20160601/

[27] W.W. Chin, The partial least squares approach to structural equation modeling. In G. A. Marcoulides (Ed.), Modern methods for business research. 1998.

[28] K.A. Bollen, and R. Lennox, "Conventional wisdom on measurement: A structural equation perspective.” Psychological Bulletin, (110)2 , 1991, 305-314.

[29] J.F. Hair, G.T.M. Hult, C.M. Ringle, and M. Sarstedt, A Primer on Partial Least Squares Structural Equation Modeling (PLS-SEM). Thousand Oaks: Sage, 2013. 


\section{Appendix: Survey Questionnaire}

(A.1) Overall, how do you feel about mobile information services (MIS) and the overall Quality of Life?

\begin{tabular}{|l|l|}
\hline Overall Contribu- & Items \\
\cline { 2 - 3 } tion & $\begin{array}{l}\text { 1) Using the MIS helps me make my life close to ideal. 2) Using } \\
\text { the MDS improves the general conditions of my life. 3) Using the } \\
\text { MDS helps make my life more satisfying. 4) Using the MDS helps } \\
\text { me achieve important things in my life. }\end{array}$ \\
\hline
\end{tabular}

(A.2) Original and added/modified (under broken line) individual life domains from Choi et al. (2007)

\begin{tabular}{|c|c|}
\hline $\begin{array}{l}\text { Original Life Do- } \\
\text { mains }\end{array}$ & Items \\
\hline Cultural & $\begin{array}{l}\text { 1) Purchasing movie or concert tickets over the MIS whenever I } \\
\text { want, improves my cultural life; } 2 \text { ) Making reservations for mov- } \\
\text { ies and concerts through the MIS while I am out improves my } \\
\text { cultural life; 3) Getting discount vouchers through the MIS before } \\
\text { going to a restaurant or cinema improves my cultural life; 4) Get- } \\
\text { ting movie information through the MIS on the street improves my } \\
\text { cultural life; 5) When it's too bothersome to go to the cinema, } \\
\text { reserving tickets through the MIS improves my cultural life. }\end{array}$ \\
\hline Leisure & $\begin{array}{l}\text { 1) Using the MIS to lift my spirits when I am gloomy improves my } \\
\text { leisure life; 2) Using the MIS to spend my spare time while I am } \\
\text { out helps my leisure life; } 3 \text { ) MIS help me to stay close with my } \\
\text { personal interests, preferences and hobbies which improves leisure } \\
\text { life. } \\
\text { 4) Using SNS (Social Networking Service) such as Facebook or } \\
\text { Twitter over the MIS in my spare time improves my leisure life. } \\
\text { 5) Using MIS to play games, listening music, or watching video } \\
\text { streaming or TV in my spare time improves my leisure life. }\end{array}$ \\
\hline Consumer & $\begin{array}{l}\text { 1) Frequently checking prices through the MIS while I am shop- } \\
\text { ping improves my life as a consumer; 2) Buying goods through the } \\
\text { MIS instead of actually going out for shopping improves my life as } \\
\text { a consumer; 3) Searching for information on goods I want to buy } \\
\text { through the MIS, improves my life as a consumer; 4) Exchanging } \\
\text { goods over the MIS improves my life as a consumer. }\end{array}$ \\
\hline Financial & $\begin{array}{l}\text { 1) Using the MIS to send money electronically to another person } \\
\text { when Iam away improves my financial life; 2) Using the MIS to } \\
\text { check my bank account improves my financial life; 3) Using the } \\
\text { MIS to buy and sell stocks/options instantly improves my financial } \\
\text { life; 4) Making reservations for trains with low commissions on } \\
\text { the MIS improves my financial life. }\end{array}$ \\
\hline
\end{tabular}




\begin{tabular}{|c|c|}
\hline Health & $\begin{array}{l}\text { 1) Recording health data daily through the MIS improves my } \\
\text { health life; 2) Using the MIS to take the medical advice when I } \\
\text { can't use a PC improves my health life; } 3 \text { ) Instead of going to the } \\
\text { clinic or hospital, making an appointment by the MIS will improve } \\
\text { my health life. }\end{array}$ \\
\hline Safety & $\begin{array}{l}\text { 1) Using the MIS to search my location when I get lost at a strange } \\
\text { place improves my personal safety; 2) Searching for a safe route to } \\
\text { my destination through the MIS late at night improves my personal } \\
\text { safety; 3) Being in contact with other people through the MIS } \\
\text { when I am alone improves my personal safety. }\end{array}$ \\
\hline \multirow[t]{2}{*}{ Family } & $\begin{array}{l}\text { 1) When I am concerned about my family members, searching for } \\
\text { their current location using the MIS improves my family life; } 2 \text { ) } \\
\text { Getting in touch with my family members through the MIS to } \\
\text { relieve their worries improves my family life; } 3 \text { ) Sending photos to } \\
\text { my family over the MIS help my family life; 4) To be in constant } \\
\text { contact with my family when I am away improves my family life. }\end{array}$ \\
\hline & $\begin{array}{l}\text { 5) Using SNS such as Facebook or Twitter over the MIS improves } \\
\text { my family life. 6) Getting in touch with my children or grand- } \\
\text { children by e-mail or video streaming through MIS improves my } \\
\text { family life. }\end{array}$ \\
\hline Friend & $\begin{array}{l}\text { 1) Frequently sending photos to friends over the MIS improves my } \\
\text { friendships; 2) Frequently contacting friends through the MIS } \\
\text { improves my friendships; 3) Congratulating friends on their } \\
\text { birthday over the MI improves my friendships. }\end{array}$ \\
\hline \multirow[t]{2}{*}{ Self } & $\begin{array}{l}\text { 1) Using the MIS to share my own photos with others improves my } \\
\text { self-expression; 2) Immediately upgrading to the latest services } \\
\text { over the MIS increases my self-esteem. }\end{array}$ \\
\hline & $\begin{array}{l}\text { 3) Using SNS such as Facebook or Twitter over the MIS increases } \\
\text { my self-esteem. 4) Using the latest tool such as snapchat to share } \\
\text { photo or video streaming over SNS improves my self-expression. }\end{array}$ \\
\hline Community & $\begin{array}{l}\text { 1) Informing members of on-line community meeting dates over } \\
\text { the MIS, improves my community life; } 2 \text { ) Checking bulletin } \\
\text { boards and e-mail from the on-line community over the MIS im- } \\
\text { proves my community life. }\end{array}$ \\
\hline Work & $\begin{array}{l}\text { 1) Searching for recruiting information through the MIS helps my } \\
\text { work life; 2) Discussing job-related issues with co-workers } \\
\text { through the MIS helps my work life; 3) Working through the MIS } \\
\text { when I can't use a PC helps my work life }\end{array}$ \\
\hline
\end{tabular}


(A.3) Original individual life domains from Ghyas and Kondo (2016)

\begin{tabular}{|l|l|}
\hline Proposed Life Domains & Items \\
\hline Trustworthy & $\begin{array}{l}\text { 1) Having trust on the Internet services by MIS, improves } \\
\text { my trustworthy life; 2) Having trust on paying for the on-line } \\
\text { shopping via MIS, will improves my trustworthy life; 3) } \\
\text { Having trust on MIS while I am reading, entertaining and } \\
\text { getting information via internet, will improves my trust- } \\
\text { worthy life. }\end{array}$ \\
\hline Information & $\begin{array}{l}\text { 1) MIS helps me to get information of news, weather, maps, } \\
\text { etc. when I need which improves my information life; 2) I } \\
\text { can search personal information through MIS when I need } \\
\text { which improves my personal life; 3) at anytime, anywhere, } \\
\text { be Searching information at anytime, anywhere by the MIS } \\
\text { is fully useful in order to improve my informational life }\end{array}$ \\
\hline Health Monitoring & $\begin{array}{l}\text { 1) Using MIS to monitor blood pressure, glucose level, } \\
\text { weight, food calorie etc. by own self when I am home, im- } \\
\text { proves my health life; 2) Using MIS in home for diet control } \\
\text { and medication agenda, etc., improves my health care }\end{array}$ \\
\hline Educational & $\begin{array}{l}\text { 1) Translate words through mobile dictionary anywhere } \\
\text { anytime, improves my educational life; 2) Reading news- } \\
\text { papers, e-books through MIS, improves my educational life; } \\
\text { 3) to see the education program by the MIS when I cannot } \\
\text { use the PC, will improves my educational life. }\end{array}$ \\
\hline
\end{tabular}

